\title{
El Mapa de América Meridional de Juan de la Cruz Cano de 1775, y los problemas territoriales de España en Brasil
}

\author{
José Andrés Jiménez Garcés*
}

Recibido el 12 de febrero de 2017; aceptado el 20 de abril de 2017

\begin{abstract}
This article presents the problems encountered by the geographer Juan de la Cruz Cano, during the process of elaboration and delivery to the Secretariat of State of the Map of South America concluded in 1775. The difficulties with which they collided, both the author and his work, were due to the existing division within the Spanish Court. The different groups of power that gathered around the king had different and opposing views on what was to be represented in the map. Both groups also differed with respect to the administration of South America.

Key words: cartography, diplomacy, information, state policy.

\section{Resumo}

O presente artigo expõe os problemas com que se deparou o geógrafo Juan de la Cruz Cano, durante o processo de elaboração e entrega a Secretaria de Estado da Espanha do Mapa da América Meridional concluído em 1775. As dificuldades com que colidiram, tanto o autor como sua obra, foram devidas a divisão existente dentro da Corte Espanhola. Os diferentes grupos de poder que se reuniam em torno do rei tinham opiniões distintas e desencontradas sobre o que havia de representar-se no mapa. Ambos os grupos diferiam igualmente a respeito da administração da América do Sul.

Palavras chave: cartografia, diplomacia, informação, política de estado.
\end{abstract}

* Departamento de Geología y Medio Ambiente, Universidad de Alcalá, España, correo electrónico: jandresjimenez@msn.com. 


\section{Resumen}

El presente artículo expone los problemas con que se encontró el geógrafo Juan de la Cruz Cano, durante el proceso de elaboración y entrega a la Secretaría de Estado del Mapa de América Meridional concluido en 1775. Las dificultades con que las que chocaron, tanto el autor como su obra, fueron debidas a la división existente dentro de la Corte Española. Los diferentes grupos de poder que se reunían entorno al rey tenían opiniones distintas y encontradas sobre lo que había de representarse en el mapa. Ambos grupos diferían igualmente respecto a la administración de América del Sur.

Palabras clave: cartografia, diplomacia, información, política de estado.

\section{Introducción}

Una de las mejores obras cartográficas realizadas a lo largo de la Historia Moderna ha sido el Mapa de América Meridional, realizado por Juan de la Cruz Cano y Olmedilla entre 1764 y 1775. Sin duda, no existió representación mejor y más completa de América del Sur anterior al uso de la fotografía aérea en cartografía. Las medidas y datos que los españoles aportan en aquellos momentos en el mapa, eran más fidedignas dentro de sus niveles de error, que las que se conocían de la misma Europa o incluso de España.

Pero el mapa resultó ser un fracaso publicitado por algunos políticos que dirigían la administración española en aquellos momentos, y el autor de la obra pasó a ser un renegado de la cartografía, y su vida no tuvo la relevancia social que buscaba con la realización de su obra. Para la construcción de esta magna obra, Juan de la Cruz siguió las pautas que sus maestros le inculcaron, creyendo que, al realizar una labor tan completa triunfaría, y ascendería socialmente. Pero el plasmar en el mapa aquella cantidad de datos, de la forma científica enseñada por Jorge Juan y Antonio de Ulloa y siguiendo la técnica cartográfica aprendida en el taller de Jean Baptiste Bourguinon D’Anville, no trajo a Cruz Cano nada más que problemas, como él mismo comprendió durante la realización de su obra.

En gran medida, la mayor parte de las dificultades que se asociaron al mapa tras su construcción, se relacionaron con las líneas que se señalaban entre los territorios españoles y portugueses en una de las primeras ediciones. En realidad no solo fueron estas líneas, rápidamente borradas, las generadoras de conflictos en el seno de la corte española, sino que el señalar zonas ocupadas o que habían sido utilizadas en ciertos momentos por portugueses, más al oeste de lo que se pensaba, exasperó a un grupo político español importante, que mantenía ciertas tensiones con otro sector con pensamientos distintos. 


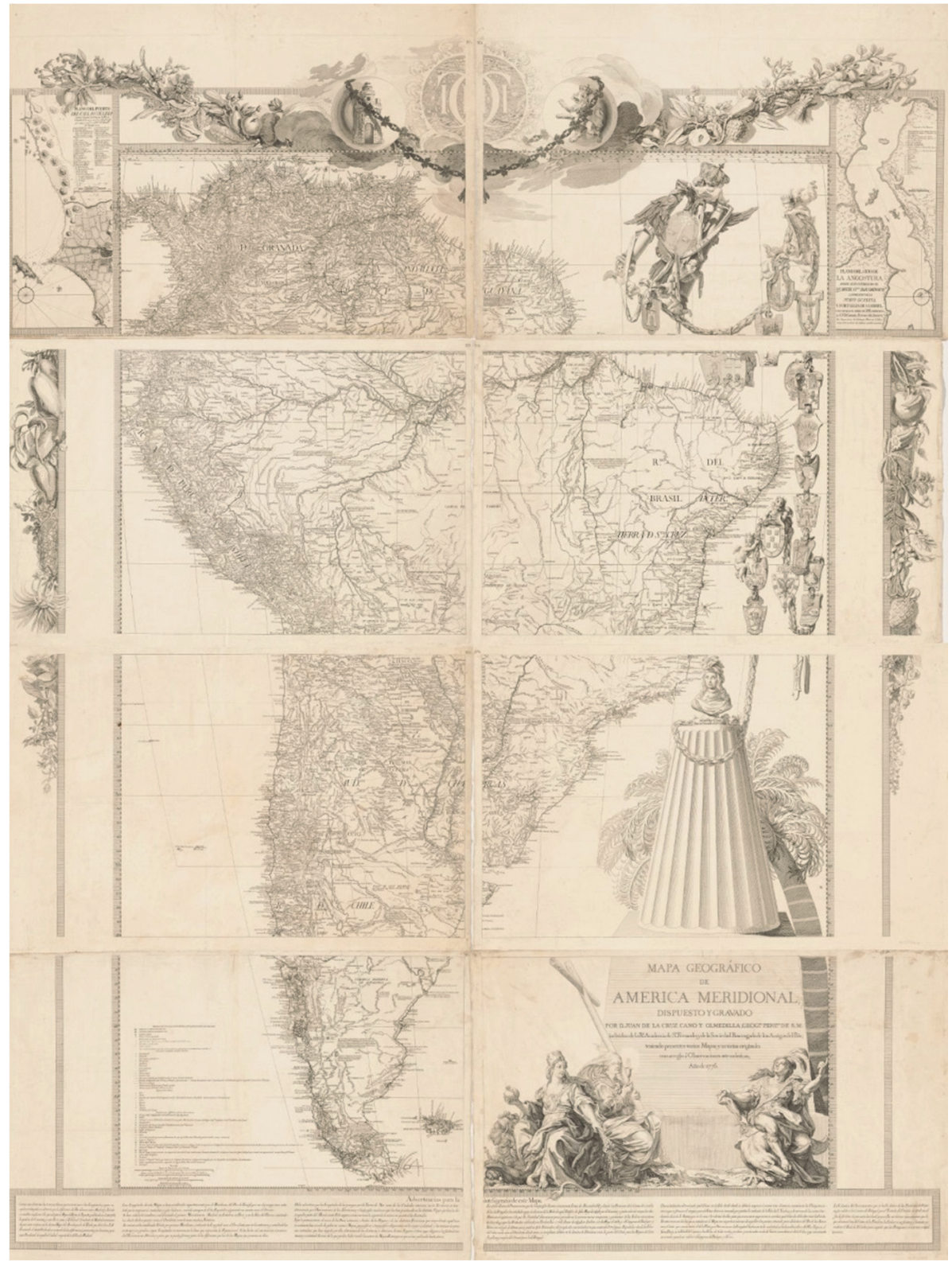

Figura 1. Único ejemplar del Mapa Geográfico de América Meridional de Juan de la Cruz Cano, en el que aparecen completas, y no borradas las líneas de división entre las Misiones del Perú y Brasil. Mapa de la cartoteca Windsor de la Universidad de Harvard.

Fuente: $<$ http://ids.lib.harvard.edu/ids/view/ $>$. 


\section{La división en el seno de la Corte Española}

La existencia de grupos políticos en el seno de las distintas cortes europeas era algo que se producía en general, no solo en la modernidad, sino que las diferencias de criterios entre distintos grupos, $\mathrm{y}$, sobre todo, la defensa de intereses de grupo distintos, se produce desde el comienzo de las distintas asambleas que aconsejaban al rey. Los problemas relacionados con estas divisiones eclosionaron siempre que no se buscaba un destino común, y cuando unos han intentado tomar el poder a costa de los otros.

En el caso de aquella segunda mitad del siglo XVIII en los palacios madrileños por donde se movía Carlos III, había al menos dos grupos políticos distintos, en el periodo de tiempo que transcurre entre la construcción del mapa que aquí tratamos, y su uso posterior en cuestiones relacionadas con la política americana, con visiones diferentes respecto a cómo tenía que ser nuestra actuación en aquellos territorios americanos. Por un lado, la defendida por el Secretario de Estado, marqués de Grimaldi, defensor de volver en los acuerdos con Portugal a la línea del Tratado de Tordesillas. ${ }^{1}$ Y la postura del que fuera presidente del Consejo de Castilla, posteriormente embajador en París, y principal diplomático español durante las conversaciones previas al Tratado de 1777, conde de Aranda, consistente en ceder los territorios necesarios, para poder defender y rentabilizar bien el resto.

Grimaldi era un político inteligente, y realmente sabía que volver a la línea de Tordesillas, señalada junto con otras en el mapa de Cruz Cano, era casi imposible, pero por otro lado no quería reconocer las incursiones portuguesas hacia el oeste, pues de lo contrario daba la razón en parte a Portugal, y al otro sector político, dirigido por Aranda.

Por el contrario, el conde aragonés desde la embajada de París y su grupo de nobles, reconocían las incursiones lusitanas por el Brasil, y pensaban que había que realizar cesiones, o administrar el sur americano de otra manera.

Aranda y su grupo no solo eran contrarios a la visión de Grimaldi y los suyos, sino que pretendían el poder, la añorada Secretaría de Estado que le entregaría Carlos IV al conde en 1792.

\section{Las líneas que representa Cruz Cano en el Mapa de América Meridional de 1775}

En algún momento, alguien podría considerar que las líneas de demarcación que se representan en el mapa podían ser lo que el autor de esta obra, estudiando pactos, tratados, historia y cartografías, pudo considerar como la frontera en Brasil entre España y Portugal. Una vez analizado el trabajo de este gran geógrafo y la situación

1 Cualquiera de las dos posibles líneas era válida. Y si se tenía que realizar alguna cesión, siempre a cambio de algo de igual valor. 
política de aquellos momentos, podemos considerar que no fue así como ocurrieron los acontecimientos en las diferentes fases de construcción de la obra, por lo que se refiere a dichas líneas de demarcación situadas en el mapa.

Cruz Cano dibujará aquello que le indican los documentos existentes hasta aquellas fechas y que le dejan estudiar, y terminará reflejando aquello que le dejan poner en el mapa. Otra cosa es, que ciertas personas le proporcionasen la información que ellos querían que se situase en el mapa, o que otras no le proporcionasen toda la información existente, al no querer que se ubicasen ciertos datos en la obra.

Dependiendo de las ediciones de los mapas podemos observar señalados en ellos dos tipos de "líneas demarcadoras". En todas las ediciones se dibujan las dos líneas del Tratado de Tordesillas, ya se tomasen las 370 leguas desde la isla más occidental o desde la más oriental del archipiélago de Cabo Verde. ${ }^{2} \mathrm{Y}$ solamente en la primera edición se dibuja una línea, que termina siendo doble, cuya función, según la leyenda, era diferenciar las misiones españolas, de la zona de misiones portuguesas. La línea, fue mandada borrar por Grimaldi una vez concluido el mapa, y se añadió desde entonces una leyenda de colores.

Las líneas de Tordesillas que aparecen en el Mapa, las dos cortan América Meridional con dirección norte-sur antes de la desembocadura del río Amazonas, sus puntos norte se encuentran en la Hoja 4 y los más al sur, en la Hoja 6 del mapa.

La primera de estas dos líneas de Tordesillas más oriental, comienza en el Cabo de Cuma en la costa atlántica, en $2^{\circ} 10^{\prime}$ Sur y $45^{\circ} 20^{\prime}$ Oeste, ${ }^{3}$ unos $80 \mathrm{~km}$ al noroeste de la ciudad de San Luis, capital de la Capitanía de Marañan. La línea vertical ${ }^{4}$ se prolonga hacia el sur, atraviesa la cabecera del río de la Palma, más al sur, el río de los Remedios y río de la Concepción, río de los Piloes, y atraviesa el cauce alto del río San Francisco, cerca de la Sierra Bermeja, al sur de la Hoja $\mathrm{N}^{\circ}$ 4; pasa a la Hoja $\mathrm{N}^{\mathrm{o}}$ 6, a unos $111 \mathrm{~km}$ de Villa Rica, continúa hacia el sur tocando el nacimiento del río Parayba, en el suroeste de la Capitanía del Río Janeiro, y su punto sur, por lo que nos concierne, será el oeste de la Isla de San Sebastián, en $24^{\circ} 20^{\prime}$ Sur y $45^{\circ} 20^{\prime}$ Oeste.

La segunda línea de Tordesillas, al oeste de la anterior, tiene su punto norte en la desembocadura del pequeño río Carara en el Atlántico, sobre $1^{\circ} 10^{\prime}$ Sur y $46^{\circ} 50^{\prime}$ Oeste, se prolonga hacia el sur, pasando por el cauce alto del río Mejari, atraviesa el

2 Isla de San Antonio, la más occidental, y la de San Nicolás, la más oriental. Hay otras islas más al este en dicho archipiélago, la más oriental sería la de Buenavista, pero parece que se tomó la de San Nicolás por ser está la más oriental de lo que en un principio se consideró como archipiélago. Véase "Carta Esférica de la costa de África" del Atlas marítimo de España.

3 Todas las medidas, coordenadas y topónimos reflejados en este trabajo están tomados del Mapa de América Meridional de Juan de la Cruz Cano, y siguen su información.

4 Representada por tres puntos raya tres puntos 
río Parnatinga y, más al sur el río Preto; pasa a la Hoja $\mathrm{N}^{\circ} 6$ donde en su trayectoria, se interpone la ciudad de San Pablo, capital de la Capitanía de San Vicente. El punto final sur de esta línea, era la desembocadura del río Ytaman en $24^{\circ} 35^{\prime}$ Sur y $46^{\circ} 50^{\prime}$ Oeste.

La otra línea de demarcación que se podía observar en el Mapa, sólo en la primera edición, ${ }^{5}$ no se puede considerar una frontera política como tal, pues según indica Cruz Cano en la leyenda de la citada edición se trata del "Termino de Misiones entre Perú y Brasil"

Este límite, que será borrado rápidamente, en un principio solo señalaba las misiones del Perú y Brasil, y se extiende por la parte este de la Hoja $\mathrm{N}^{\mathrm{o}} 3$, Hoja $\mathrm{N}^{\mathrm{o}} 6$, una pequeña parte en el este de la $\mathrm{N}^{\mathrm{o}} 5$, parte sureste de la $\mathrm{N}^{\mathrm{o}} 1$ y suroeste de la $\mathrm{N}^{\mathrm{o}} 2$.

La línea reconocía la existencia de unas misiones dependientes del Perú y otras del Brasil, no se indicaba que nación era la propietaria de esas misiones, pero en la zona al este de esa línea se podían observar una serie de territorios ocupados por súbditos portugueses al oeste de los ríos Tocantines y los afluentes por la izquierda del Paraná en su cabecera, Tiete û Añemby y Cabeceras del Paraná. Territorios como los señalados en la Hoja $\mathrm{N}^{0}$ 4, Aldea de Sanante de Cua, más al oeste, el Jesús de Cuyabá ${ }^{6}$ y en longitud parecida, pero más al sur, "La estancia en donde los Portugueses pasan en hombros dos leguas las canoas para penetrar por el Río Camapua hasta el Matogroso, Cuyaba, \&.”. En la Hoja No 6 la toponimia en la que se observa una ocupación portuguesa es más abundante, al sur de las cabeceras del Paraná, formando parte de las Capitanías de San Vicente y del Rey ambas al oeste de las líneas de demarcación de Tordesillas.

La línea se marca una vez analizada la información de los mapas realizados por los misioneros de la Compañía de Jesús, junto con los construidos por los comisarios de las Partidas de Límites, con posterioridad al Tratado de $1750 .^{7}$

Analizando esta línea llamada "Termino de Misiones entre Perú y Brasil", sobre el mapa de la primera edición y comenzando de sur a norte, ésta se inicia cerca de la costa atlántica, al norte de la Ciudad del río Grande de San Pedro; los tres fuertes que hay al norte de la desembocadura del río Grande de San Pedro, Guardia del Norte, Guardia de la Caballada y otro sin nombre, quedan en zona de misiones portuguesas y la ciudad del río Grande de San Pedro, en zona de misiones españolas; la línea se prolonga al norte, por el centro de la Laguna Grande de los Patos, o río Grande de

5 Se ha trabajado con el mapa de la Biblioteca de la Universidad de Harvard y con la hoja $\mathrm{N}^{\mathrm{o}} 6$ del ejemplar de la Biblioteca Nacional de España, ambos son de la primera edición.

6 Según se indica en la obra Minas de oro que trabajan los Portugueses

7 La línea, a partir del río Jucay, toma dos direcciones, dejando un espacio entre ellas a modo de zona neutral. 
San Pedro, prosigue por el centro del cauce bajo del río Jucay desde su desembocadura; cuando el cauce gira al oeste, la línea continua por la margen derecha del cauce del río Jucay, pero al llegar a la desembocadura del río Teviquari, ${ }^{8}$ la línea se divide en dos: una sigue el cauce del río Jucay hacia el norte y la otra, en un principio paralela al río Mboapiari, ${ }^{9}$ sigue al este más pegada a los territorios portugueses.

Prosiguiendo con esta última línea, más larga, a la que denominaré Línea $\mathrm{N}^{\circ} 1$, prosigue paralela al río Mboapiari y, posteriormente, una vez deja su nacimiento, sigue al noreste, hasta atravesar el cauce alto del río Teviquari en $28^{\circ} 28^{\prime}$ Sur, se prolonga hacia el norte hasta cruzar el cauce del río Uruguay, y prosigue hacia la unión de los ríos Itapeba y Canoaes Meri; continúa al noreste, cerca de los pueblos de Pitangui, Caiacanga y al este de las ruinas de San Miguel; en su trayectoria norte, pasa por el cartel que señala las "Reales Minas de Paraná Pane conforme los Misioneros"; un poco más al norte, cruza el curso alto del río Paraná Pane, prosigue por la ladera izquierda de la Sierra de Ibatucatú para, algo más al norte, continuar por el cauce bajo del río Tiete o Añemby.

Desde el río Tiete pasa a la Hoja $\mathrm{N}^{\circ}$ 4, en la que esta parte de la línea va desde el cauce del río Grande de Paraná ${ }^{10}$ hacia el oeste, por el cauce alto del río Pardo, continuando al oeste hasta pasar a la Hoja $\mathrm{N}^{\circ} 3$. En la misma, la línea llega hasta la desembocadura del río Taguari en el Morro de la Cebada, cerca del río Paraguay en el sureste de la Hoja, continuando al norte hacia la desembocadura del río de los Porrudos en el Cuyaba; sigue por el este de la cordillera de San Josef, hasta el cauce alto del río Paraguay y desciende por este río hasta Marco de Marmol, donde la línea toma dirección oeste. Desde aquí, prosigue hacia el cauce del río Ytenes por la izquierda, cerca de Villa Bella de Matogroso, continúa al noroeste, pasando a la margen derecha, cruza las desembocaduras del Zanjón de los Infieles y el río San Josef siguiendo el cauce del río Ytenes hacia el noroeste, hasta su unión con el río de la Madera. Prosigue la línea, ya por el cauce derecho del río de la Madera, en la desembocadura del río Beni en el anterior, y hacia el este, pero ahora por la margen izquierda del río de la Madera. Al llegar a la pequeña laguna Cayaá toma dirección oeste, cruza el citado río, y se prolonga $77 \mathrm{~km}$ al sur por su cauce izquierdo y toma dirección oeste para cruzar el río Tefe. Continúa hacia el noroeste, cruzando el río Yurba y $53.6 \mathrm{~km}$ más al oeste cruza el río Yutay, para avanzar hacia el oeste, por el sur de la Nación Huatates y llegar al cauce derecho del río Yavari. Una vez aquí, sigue por éste río hasta su desembocadura en el Amazonas, y desde este punto sigue por la margen izquierda del Amazonas $50 \mathrm{~km}$, pasando luego a la margen derecha. Continúa por esta parte hacia el noreste $\mathrm{y}$, al llegar al norte del territorio de los indios Guarficus, en una isla del cauce del Amazonas, cruza el río para continuar por la

8 Afluente del Jucay por la izquierda.

9 Afluente del Tevicuari por la izquierda.

10 Es la desembocadura del Tiete en el Paraná. 
margen izquierda, entre el río y las palabras de un cartel pegado a éste: “[...] llamaron igualmente los Españoles, Orellana [...]". Abandona el cauce del Amazonas y dirigiéndose al noreste, cruza el cauce del río Yupura, bordea el margen este del lago Inasabu o Marahi, cruza el río Nuissi, y mantiene la dirección noreste, llegando a la margen derecha del cauce bajo del río María. Acompaña a este río siguiendo su cauce $72.7 \mathrm{~km}$ hasta su desembocadura en el río Negro, cruza aquí el río Negro y desciende por la margen izquierda del mismo $49.4 \mathrm{~km}$, cruzando las desembocaduras de los ríos Cababuri, Abuara e Ynambú. Al llegar a la desembocadura del río Maravia, la línea asciende por su cauce derecho $20 \mathrm{~km}$, cruza este río y se dirige con dirección noreste al cauce del río Parime, atravesándolo a la altura de la $4^{\mathrm{a}}$ Boca Dara. Prosigue hacia el sur por la margen izquierda del río Parime $129 \mathrm{~km}$, hasta la desembocadura del río Guauao. En éste, se prolonga hacia el noreste por el sur del cauce del citado río, hacia su nacimiento, unos $360 \mathrm{~km}$, sale de la Hoja 3 al este del cauce del río Tocota, y pasa a la Hoja $\mathrm{N}^{\mathrm{o}} 1$ tocando mínimamente su ángulo sureste. Así la línea, desde el punto cercano anterior del río Tocota ${ }^{11}$ sigue al noroeste, bordea el cauce alto del río Tacutú y toma dirección norte hacia la sierra de Tumucaraque, pasando a la Hoja $\mathrm{N}^{\mathrm{0}} 2$, donde bordea esta sierra para concluir en la Guayana, al sur del cartel que se refiere a este territorio. Los últimos $110 \mathrm{~km}$ de la línea en territorio de la Guayana, coinciden con la "Demarcación de Provincia o Partido Grande"12 con que aparece señalado el límite de este territorio en todos los mapas posteriores a esta primera edición, una vez rectificada la línea.

La otra parte de la línea "Termino de Misiones entre Perú y Brasil", a la que denominaré Línea $\mathrm{N}^{\circ} 2$, que habíamos dejado en el río Jucay, al norte del río Grande de San Pedro, continúa hacia el oeste por la margen derecha (sur) del río Jucay, y al llegar a Guardia Española, pasa a la margen izquierda, para volver de nuevo a la margen derecha por la desembocadura del río Guacay Guazu en el Jucay. Prosigue hacia el norte por el cauce derecho del río Jucay, hacia el norte de las Tierras de la Vaquería, ${ }^{13}$ abandona el cauce del río ${ }^{14}$ al norte, continuando por el cauce izquierdo del río Uruguay Pitá. Prosigue por su cauce hasta la desembocadura del mismo en el río Uruguay; aquí la línea toma el cauce izquierdo del río Pepiry Guazú y sigue hacia el norte, desde su desembocadura frente al Uruguay Pita, hasta su nacimiento. Continúa su avance hacia el norte por la margen derecha del río San Antonio, desde su nacimiento hasta cerca de su desagüe en el río Yguazú, cruza éste y prosigue por su

11 En la Hoja $N^{\circ} 1$ al cauce alto Cruz Cano lo denominó Tacutú.

12 Límite con la Guayana. Esta frontera con los territorios franceses se prolonga por la ladera norte de la sierra de Tumucuraque.

13 Estas quedan al este, en territorio portugués.

14 La Línea ha seguido durante $423 \mathrm{~km}$ el cauce del río Jucay, desde el Río Grande de San Pedro hacia las Tierras de la Vaquería. 
cauce derecho $62.5 \mathrm{~km}$ hasta su desembocadura en el Paraná. Desde la desembocadura del Yguazú, sigue al norte por el cauce izquierdo del Paraná, cruza el Salto Grande del Paraná de siete quedas ${ }^{15}$ y en la desembocadura del río Gatime ${ }^{16}$ toma dirección oeste siguiendo el cauce de este río. Posteriormente, prosigue por un afluente en cabecera de éste, el río Guiraquela, y en el suroeste de la Isla de los Tres Hermanos, gira al suroeste por el cauce del río Yguaray, continuando hacia el oeste por el cauce del río Ypane Guazú, ${ }^{17}$ hasta concluir en el río Paraguay, muy cerca de la villa de Nuestra Señora de Belem. Aquí termina este brazo más suroccidental de la línea.

Resulta curioso que parte de la línea que denomino $\mathrm{N}^{\circ} 1$, en concreto parte de esta línea entre el río Grande de San Pedro y el río Tiete, o Añemby, que se adentra más en territorio portugués, es muy parecida, o al menos parece seguir la misma trayectoria que la línea que aparece dibujada en un mapa de los jesuitas realizado tras el Tratado de 1750. Esta obra a la que me refiero es la titulada: "Mapa de la Gobernación del Paraguay y de la de Buenos Aires con la línea divisoria de las tierras de España y Portugal..." ${ }^{18}$ y está realizada en 1752. En este mapa aparece una línea dibujada en color verde, que está trazada por un lugar parecido al que utiliza Cruz Cano para diseñar su línea $\mathrm{N}^{0} 1$. Los miembros de la Compañía de Jesús consideraron, y así lo indican en el mapa, que si la línea de frontera de 1750 siguiese esa trayectoria señalada en dicho mapa no perjudicaría ni a indios ni a portugueses, quizás esa misma idea que expresaban los jesuitas, inspiró a Cruz Cano para que parte de su línea $\mathrm{N}^{\mathrm{o}} 1$ siguiese parecida trayectoria.

Esta línea $\mathrm{N}^{\mathrm{o}} 1$ de "Termino de Misiones entre Perú y Brasil", se trata de un límite completo de frontera, ${ }^{19}$ pues, en realidad, todos los territorios al oriente de ella están ocupados por asentamientos portugueses, pero al occidente de esta línea y al este de la línea $\mathrm{N}^{\circ} 2$, se encuentran territorios, que no teniendo para España la importancia que confería a los que se encontraban al oeste de la línea $\mathrm{N}^{\circ} 2$, sí eran ricos, unos en ganado, otros en materias primas y sobre todo en naciones de indios, potenciales cristianos y súbditos de la Corona, sin olvidar que estas zonas podían actuar de territorios tapón frente a la expansión portuguesa.

Analizando este territorio entre las dos líneas, y de sur a norte nos encontramos con varias zonas:

15 Unos $206 \mathrm{~km}$ al norte de la desembocadura del Yguazú.

16 Afluente por la derecha del Paraná.

17 Sale de la Hoja 6 y su cauce continúa en la Hoja 5, al sur del Trópico de Capricornio.

18 AGS. MPD, 06, 032.

19 Aunque no se identifique así en el mapa donde se representa, y se denomine término de misiones entre Perú y Brasil. 
- La primera se encuentra en la Hoja $\mathrm{N}^{\circ}$ 6, se trata de las Tierras de la Vaquería entre los ríos Jucay y Tevicuari, al norte de estas en la margen izquierda del cauce alto del río Uruguay, el Sitio de las Veinte Mil Vacas, zona de ocupación ganadera muy importante en la época. ${ }^{20}$

- Al norte de este Sitio de las Veinte Mil Vacas, entre la margen izquierda del río Paraná y el nacimiento del río Yguazú, ${ }^{21}$ aparece el "Territorio de la Antigua Pcia. de la Guayrà, perteneciente â los del Paraguay, y Buenos Ayres que fue llamado al mismo tiempo del Tape ô Pcia. de Vera". En esta Provincia de la Vera, junto con los pueblos ya citados al tratar de la línea $\mathrm{N}^{0} 2$, Tapitay y, Boy Población Nueva situados en la margen izquierda del río Paraná, también se encuentran una serie de misiones destruidas de oeste a este del río: Nuestra Señora de Copacabana, Tambo, Villa Rica y Los Arcángeles, San Antonio, La Encarnación y San Miguel. Por esta zona igualmente pasa un camino real que circunda el norte de estas misiones destruidas y une la margen izquierda del río Paraná2 ${ }^{22}$ con otro camino real que comunica los pueblos en el entorno de las Capitanías de San Vicente y del Rey. Este territorio de la Guayra o Provincia de la Vera fue asolado por los portugueses con antelación al tratado de $1750 .{ }^{23}$

- Al norte de este camino se encuentran representadas en el mapa otras tres misiones destruidas, San Javier, San José y Loreto, ésta última en la margen izquierda del cauce medio del río Paraná Pané.

Las zonas pobladas al norte de esta hipotética zona neutral, entorno a la línea $\mathrm{N}^{\mathrm{o}} 1$, se dividen entre asentamientos lusos al este e hispanos al oeste. Así, al norte del nacimiento del río Pardo, en zona de Misiones de Brasil, hay un pueblo grande, donde Cruz Cano sitúa un cartel con el nombre del pueblo y dice así "La estancia en donde los Portugueses pasan en hombros dos leguas las canoas para penetrar por el Rio Camapua hasta el Matogroso, Cuyaba \&". El pueblo de La Estancia se sitúa $10 \mathrm{~km}$ al sur del cauce del río Camapua; ${ }^{24}$ este río, en su cauce medio, se llama Taquari y desemboca en el río Paraguay en el llamado Morro de las Cebollas. Los portugueses

20 La carne no dejó de ser un artículo de lujo, que solo se comía en ciertas fechas, hasta la introducción de ganado en América, en cuyas fértiles tierras se adaptó muy bien, y se criaba solo en muchos sitios, sin necesidad de pastoreo. Este es el caso de los territorios entorno a la margen sur del río Uruguay.

21 Cerca de la línea $\mathrm{N}^{\mathrm{0}} 1$.

22 Coincide con la desembocadura del río Ybay, que es un afluente del Paraná por la izquierda.

23 La información se encuentra en el "Mapa de América del Sur con la línea divisoria de las colonias pertenecientes a España y Portugal”. AGS. MPD, 04, 036. Se encontraba en AGS. Estado, Legajo 07399, 0014. Acompañaba a copia de Pedro Cevallos a Ricardo Walls, San Borja 20 de febrero de 1759.

24 En el mapa el río se denomina Camapoa. 
utilizaban estos cauces para, llegando al río Paraguay, remontar sus aguas y entrar por el río Cheane, ${ }^{25}$ hasta alcanzar el territorio de Cuyabá, situado claramente en zona de misiones brasileñas, con la villa del Jesús de Cuyabá, en la que como indica Cruz Cano había unas "Minas de Oro que trabajan los Portugueses". De igual manera, remontando el río Paraguay, llegaban a su cauce alto y desde aquí, penetraban en el Matogroso.

Entorno a esta línea $\mathrm{N}^{\circ} 1$ que era la parte más extensa de lo que Cruz Cano consideró "Termino de Misiones entre Perú y Brasil" se van a ir intercalando, territorios ocupados por españoles y por portugueses. Así, el territorio del Matogroso queda al norte de la línea, en zona de misiones de Brasil, con su villa principal, la aurífera Villa Bella de Matogroso, unida por un camino real a San Antonio y Santa Ana en zona del Brasil. El camino paralelo al río Ytenes, por cuyo cauce asciende la línea, terminará en la villa de La Concepción, en la margen derecha del Ytenes. Las áreas urbanas, en esta zona límite del cauce medio alto del Ytenes, hasta su desembocadura en el río de la Madera, quedan de manera que el pequeño pueblo de Casa Redonda, frente a Isla Cumplida, se dibuja en zona de misiones del Brasil. Sin embargo $64 \mathrm{~km}$ al norte por el camino real en la margen derecha del Ytenes, San José Misión de Clérigos quedaba en zona española y, al noroeste la toldería de indios Baures situada en la margen izquierda del río, volvía a estar situada en zona de Brasil. Continuando el camino hacia el noroeste y en la margen izquierda del Ytenes, junto a la desembocadura del río de San Simón, el pueblo de San Simón, abandonado, dibuja en zona española. El pueblo de San José abandonado se encontraba $100 \mathrm{~km}$ río abajo, al noroeste de San Simón, en este caso en la margen derecha del Ytenes, se encontraba también en la zona de las misiones del Perú. Pero junto a éste, $16 \mathrm{~km}$ al noroeste el pequeño pueblo Hacienda del Francés cerca de la desembocadura del río de San Miguel, queda en zona del Brasil. Partiendo de Hacienda del Francés hacia el oeste transcurridos $114 \mathrm{~km}$ por el camino real, señala Cruz Cano en el mapa la villa de La Concepción y, al sur de ella el fuerte de la Estacada de Santa Rosa, ambos en zona española y en la margen derecha del Ytenes, si bien muy pegados a la línea. Frente a La Estacada de Santa Rosa, pero en la margen izquierda, la "Estacada Española de S. Josef por Baulen" en zona de misiones del Perú, al igual que un pueblo grande en la margen izquierda del río Baures, ${ }^{26}$ el pueblo de San Miguel. Curiosamente se encuentra este pueblo $48 \mathrm{~km}$ en zona española, al sur de la línea, y en la primera edición del mapa aparece como "S. Miguel ocupado por los Portugueses" pero en las ediciones posteriores se denomina solamente "S. Miguel ocupado". En la margen izquierda del Ytenes, frente a la Estacada de Santa Rosa, en zona española, está el pueblo de Santa Rosa la Nueva, abandonado.

25 Este río cauce arriba se denomina río de Cuyaba.

26 Afluente del Ytenes por la izquierda. 
Observamos que en los últimos $550 \mathrm{~km}$ del río Ytenes hasta unirse con el río de la Madera, tan sólo aparecen habitados la villa de La Concepción, la Hacienda del Francés, el pueblo de San Miguel y la toldería de indios Baures. De ellos, la Hacienda del Francés y San Miguel, habitados claramente por súbditos portugueses; al sur de la margen izquierda del Ytenes, siguiendo los cauces de sus afluentes, los ríos Ubai y Baures, nos acercamos a la Provincia de los Moxos, cuyo límite por estos lugares no aparece, si bien todos los pueblos que surgen hacia el sur (La Magdalena, La Concepción, San Simón...) son claramente españoles. La línea prosigue por el río de la Madera, en la margen izquierda de la desembocadura del río Ytenes y el Mamoré. En el de la Madera hay un fuerte que denomina Cruz Cano "Estacada demolida", en zona española; sigue la línea por el cauce del río de la Madera hasta el pequeño lago Cayaá, gira al oeste sin aparecer zona urbana alguna, continúa hasta la desembocadura del Yavari en el Amazonas, donde, en la margen derecha de este último, se encuentran las villas de San Pablo de Omaguas y San Pedro, ambas en zona portuguesa. Continuando la trayectoria de la línea ahora hacia el este, esta cruza los brazos de la desembocadura del río Yutay, en la margen derecha del Amazonas, encontrándose en esta zona los pequeños pueblos de Eviratóa, en el primer brazo y Traquatóa en el segundo, ambos en terrenos ${ }^{27}$ de las misiones de Brasil, mientras que San Cristóbal, cerca de la desembocadura del río Ovaripana en el Amazonas por su cauce izquierdo-norte, está en zona de misiones del Perú. ${ }^{28}$

La línea pasa a los afluentes del Amazonas por la izquierda, Yupur, Negro y Parime, cortando sus cauces hasta la Guayana a través de la Sierra de Tumucuraque. En todo este último trayecto no aparece zona urbana alguna cerca de la línea, salvo en el cauce del río Negro donde el pueblo de Avanda, $23 \mathrm{~km}$ al sur de la línea, queda claramente en zona portuguesa al igual que Nau, Bararoa, Aldeas de Carajais o Cámara y la ciudad de Barcellos, todos en la margen derecha del río Negro, en los $160 \mathrm{~km}$ al sur de la línea, claramente en un territorio muy poblado por portugueses.

27 Eviratóa y Traquatóa se representan en la margen derecha- sur del Amazonas.

28 Grimaldi, en su "Respuesta a la Memoria que presentó el 16 de Enero de 1776 el Exmo. Señor Don Francisco Inocencio de Souza Coutiño, Embaxador de S.M.F. cerca del Rei N. S. relativa á la Negociacion entablada para tratar del arreglo y señalamiento de Límites de las Posesiones Españolas y Portuguesas en América Meridional" (GRIMALDI, 1776. Ref. BNE. R/36665) al referirse a la frontera que se trazó sobre los mapas en el Tratado de 1750, dice: "La línea corta muchos parajes habitados como era el caso de la Margen Oriental del Uruguay con los siete pueblos de las Misiones y el de Sta. Rosa el viejo, en el de los Moxos... y quedaba para España el de S. Cristobal, que aquella nación había fundado indebidamente en el río de las Amazonas". De igual manera, el Secretario de Estado español se está refiriendo a la Estacada de Santa Rosa o a la villa de La Concepción, como hemos visto en la margen derecha del cauce bajo del río Ytenes. 
Por lo analizado, la línea de "Termino de Misiones entre Perú y Brasil” que, dividiéndose en dos, hemos denominado al tramo más largo $\mathrm{N}^{\mathrm{o}} 1$ y al más corto y occidental $\mathrm{N}^{\mathrm{o}} 2$, señala las zonas de misión en las que misioneros de España y Portugal habían ocupado territorios en nombre de cada una de las coronas, con el fin de evangelizar indios y hacerlos súbditos de los respectivos monarcas. Éste era el mandato principal que aparece en las Bulas otorgadas por los Papas Nicolás V, Calixto III y Alejandro VI, a los monarcas portugueses y españoles. Extraño es observar que Juan de la Cruz Cano, en lugar de señalar una línea con una sola dirección, realice dos trayectorias. La explicación más lógica es que el autor, ateniéndose a la información recogida por él de mapas, corografías, testimonios recibidos de personas que estuvieron en la zona ${ }^{29}$ señala, como dice la leyenda de la primera edición del mapa, las zonas evangelizadas hasta esos momentos tanto por misioneros españoles procedentes del Perú y súbditos del rey de España, como las cristianizadas por misioneros procedentes de la ciudades costeras brasileñas y del mismo Portugal, súbditos del monarca portugués. Pero entre las dos líneas, quedarían los territorios correspondientes a la Provincia de la Vera, ${ }^{30}$ dónde, como he indicado anteriormente, hubo misiones, pero fueron destruidas y en los momentos de realizarse el mapa no estaban ocupadas por nadie, por lo que Cruz Cano dejó estas zonas fuera de las líneas. Posiblemente esta Provincia de la Vera y los terrenos anexos, estaban situados en la primera edición del mapa entre las dos líneas, como una zona sin ocupar en aquellos momentos por españoles ni portugueses, y posiblemente con la idea de ser esta una zona neutral entre ambas naciones.

Como ya se ha indicado, las líneas fueron borradas por orden de Grimaldi, quien pretendía conseguir de nuevo el mayor territorio posible en Brasil, durante las negociaciones previas al Tratado de 1777. El Secretario de Estado español quería situar la frontera en Brasil en las líneas de Tordesillas, o lo más cerca posible de éstas. Por lo que según él no podía utilizarse un mapa para preparar el tratado donde apareciesen las líneas de misiones representadas por Cruz Cano en la primera edición de su mapa. Pero a pesar de ser estas borradas, la opinión de Grimaldi no era la única existente en la corte de Madrid sobre el tema de la frontera brasileña.

\section{Las líneas borradas y el Tratado de 1777}

Llama la atención, al leer los documentos de preparación de las conversaciones previas al Tratado de 1777, como en esa cesión de territorios en la América del Sur, en aquellos momentos, parecen tener menos importancia para España una serie de zonas Buenos Aires. Zona de misiones jesuíticas, pero que, en torno a 1630, había sido atacada por bandeirantes portugueses y defendidas y vueltas a ocupar por los indios guaraníes. 
productoras de materias primas minerales, como las Reales Minas de Paraná Pane, las minas de oro de Villa Bella de Matogroso, otras minas de oro unos $125 \mathrm{~km}$ al noroeste de las anteriores, Villa del Oro y una mina de oro $64 \mathrm{~km}$ al norte de las anteriores. Por el contrario se preferían las zonas ganaderas entorno a los cauces medio y bajo del rio Uruguay y, sobre todo, lo más importante, las zonas de misiones en este mismo territorio, pobladas por indios ya evangelizados, y según todos los informes, con una producción económica no superada en la zona en el tiempo en que fueron creadas y dirigidas por los jesuitas. ${ }^{31}$ No podemos olvidar que, desde que en 1761 se revoca el Tratado de 1750, Pedro Cevallos permitió que volvieran a las misiones algunos jesuitas y en torno a 1,500 indios. Posiblemente, la política posterior a 1760, ya con Carlos III, era volver a ocupar y revitalizar económicamente esos territorios y también los de la Provincia de Vera, si bien esta última zona no aparece poblada en el mapa. ${ }^{32}$ Según explica Diego de Alvear, esta zona tuvo una alta demografía, en torno a 300,000 individuos, y en el siglo XVII la evangelización por parte de los miembros de la Compañía de Jesús fue muy intensa. Las Reducciones creadas por los misioneros fueron atacadas, desde su creación, por mamelucos y paulistas; muchos de los ataques fueron rechazados, pero se incrementaron a partir de 1628-1630. Las incursiones de los portugueses tenían como fin la captura de indios para esclavizarlos, de hecho un testigo informó al rey Felipe IV de la venta de 60,000 indios esclavos en Río de Janeiro el año 1637. La persecución fue tal que se trasladaron las Reducciones de la Guayra a la zona de Yabebiry, emigrando unas 12,000 almas. A principios del año 1738 una segunda trasmigración se produjo a las zonas más orientales del Paraná y Uruguay.

31 Posiblemente, en esos momentos, con un pensamiento económico fisiócrata, pensasen que era mejor una economía generadora de productos agrícolas y manufacturados que una puramente extractiva. En este caso, la forma de producir en las "Reducciones Jesuíticas" había sido más humana con los indios que otras formas de explotación. No podemos olvidar como en su libro Noticias Secretas de América, Jorge Juan y Antonio de Ulloa critican la forma relajada de evangelización que tenían los franciscanos en la zona amazónica del Perú y ensalzaban la labor de los jesuitas en la zona de Mainas y recomendaban que se confiara la evangelización de la Amazonía a la Compañía de Jesús por su "fervor constante para permanecer en tales empresas sin que la inconstancia de los indios los desaliente" (Juan y Ulloa, 1826).

32 La evangelización de todo el territorio de la Guayra, si bien en el siglo XVI se intentó de manera esporádica, es en el siglo XVII, a partir de 1609, cuando se produce de forma eficiente y sostenida por parte de los jesuitas José Cataldino y Simón Maceta, que recorrieron, en muchos casos. los mismos lugares que antes habían intentado evangelizar sus antecesores, Padres Ortega y Filde. Penetraron por las riveras del Paraná-Pane siendo bien aceptados, por lo que nos indica el Comisario de Límites del Tratado de 1777, Diego de Alvear (Alvear, 1863, p. 39). 


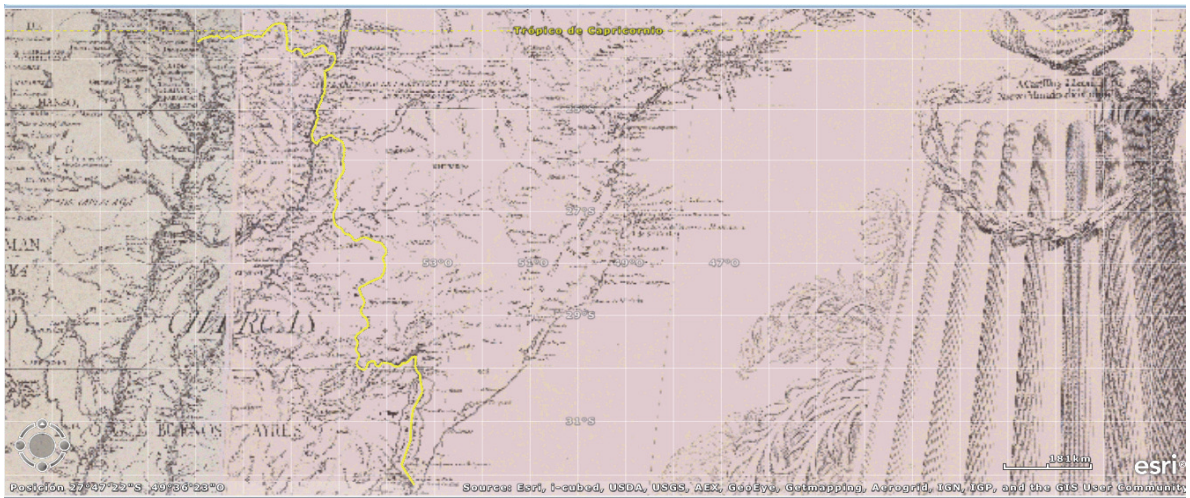

Figura 2. Línea corta borrada por Juan de la Cruz Cano del Mapa de América Meridional de 1775, por mandato del marqués de Grimaldi. Dividía las misiones del Brasil y Perú.

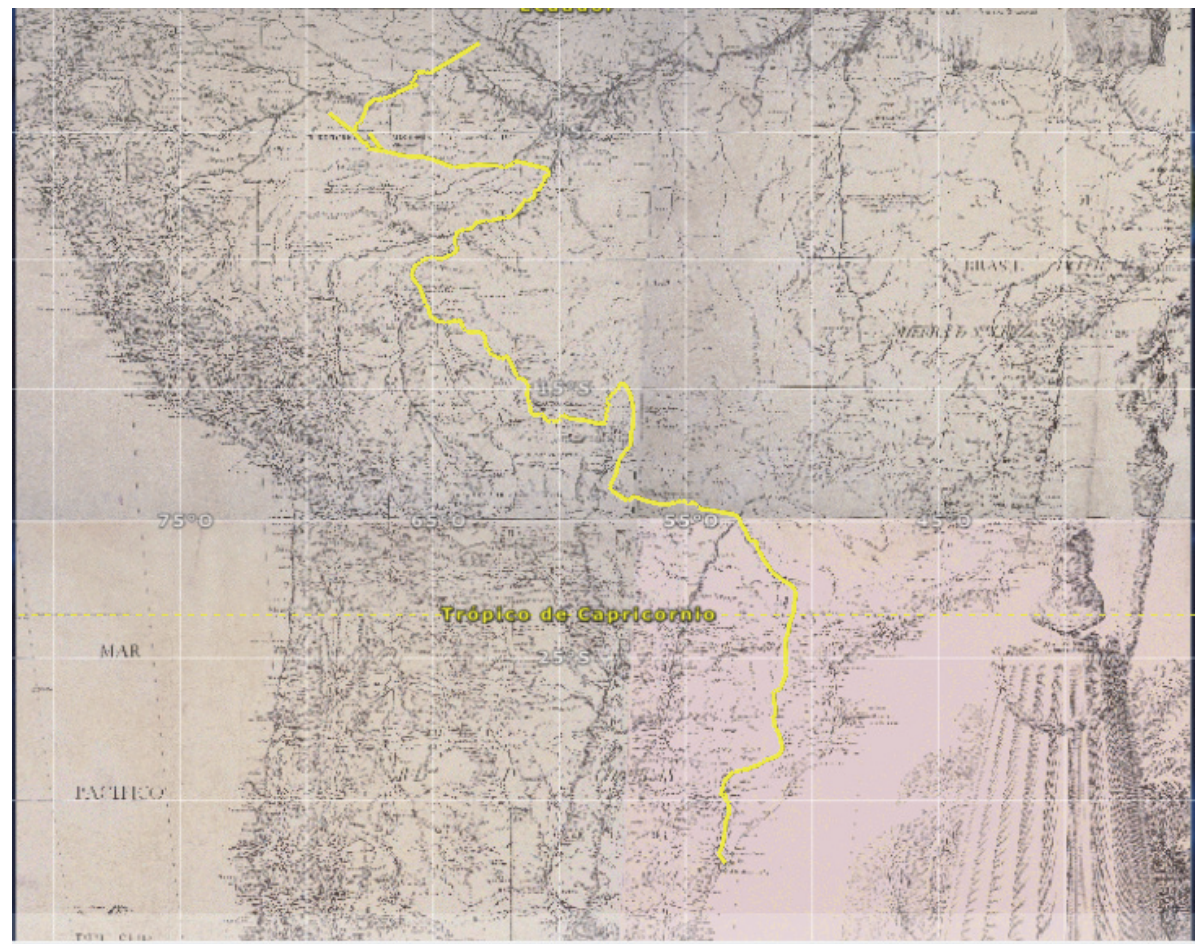

Figura 3. Línea larga borrada por Juan de la Cruz Cano del Mapa de América Meridional de 1775, por mandato del marqués de Grimaldi. Dividía las misiones del Brasil y Perú. Por el norte seguía, más o menos, el cauce del Amazonas. 


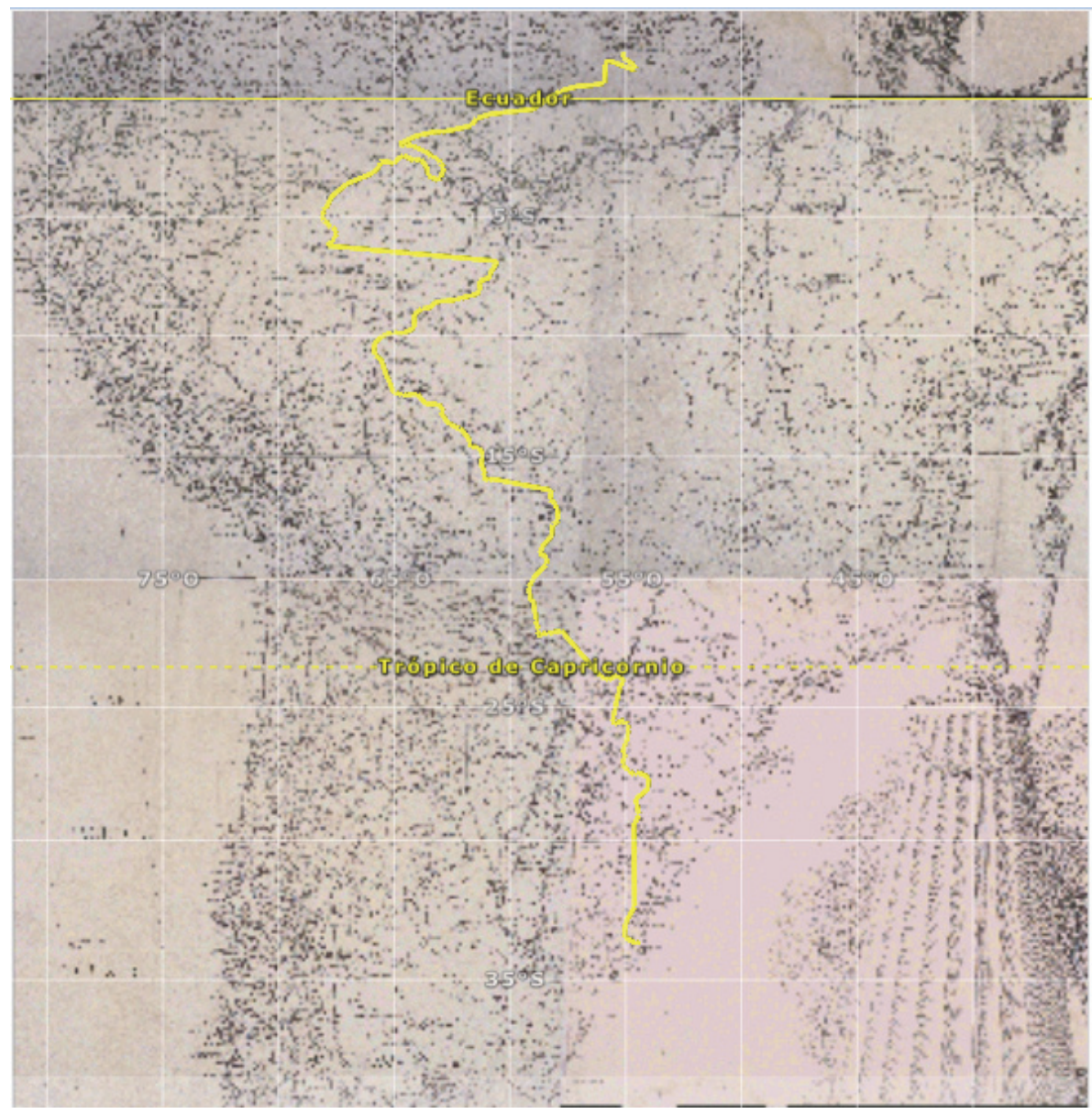

Figura 4. Línea realizada por el autor de este artículo sobre el Mapa de América Meridional de Juan de la Cruz Cano de 1775, siguiendo los artículos del Tratado de 1777. Está teórica frontera, nunca se llegó a materializar, al igual que ninguna de las pactadas entre Portugal y España.

Por el Tratado de 1777 se cederán por parte de España, territorios inmensos en extensión y producción de materias primas algunos de ellos ocupados por Portugal, en muchos casos difíciles de defender y ocupar, con el fin de mantener la Colonia de Sacramento y las zonas de misiones, por el valor estratégico la una, y económico y posiblemente demográfico, las segundas. En febrero de 1767 fueron expulsados los jesuitas de los territorios de la Corona española y las misiones pasaron a ser administradas espiritualmente por franciscanos, dominicos y mercedarios. Durante el siglo XVIII no volverán a tener la prosperidad anterior, si bien, en 1788 estos territorios, 
según Diego de Alvear, eran ricos en agricultura, ganadería, hierba mate y manufacturas de algodón, pagando un tributo al rey de un peso de plata al año cada indio varón de entre 18 y 50 años, y diezmos a la iglesia de 100 pesos de plata por reducción al año. ${ }^{33}$

La importancia que, para ciertos sectores de la corte, tenían estos territorios ocupados por misiones, se puede observar al analizar el proceso de cambio de administración que se produce en la zona en el siglo XVIII. En estos pueblos afectados por el Tratado de 1750 y por la posterior guerra, su administración fue dividida en dos en 1768 por el gobernador de Buenos Aires, Francisco de Paula Bucarelli: por un lado los diez pueblos de las misiones del Uruguay con sede en San Miguel, y por otro lado los veinte restantes con sede en Candelaria; San Joaquín y San Estanislao se unieron al Gobierno de Asunción. En 1770, el mismo Bucarelli, creó la figura de un Gobernador de Misiones, para centralizar la organización, quien dividió de nuevo las misiones en tres departamentos, dependientes de San Miguel, Santiago y Yapeyú. En agosto de 1776 se creó interinamente el Virreinato del Río de la Plata, con algunos territorios del Virreinato del Perú, estando la sede en Buenos Aires; este Virreinato se afianzó por la cédula dictada en San Lorenzo en octubre de 1777, donde quedaba definitivamente establecido el mismo y los territorios de misiones, situados dentro de éste.

La línea “Termino de Misiones entre Perú y Brasil” que borrará Cruz Cano de las planchas tras la primera edición, coincidirá en muchos de los puntos por donde pasa, con los lugares que se pactaron en el Tratado de 1777. Del mismo modo, en el artículo VI del Tratado se especifica dejar una zona neutral, entre los límites de ambas naciones, que coincidiría con esa zona neutral y despoblada, entre las líneas $\mathrm{N}^{\mathrm{o}} 1$ y 2 del mapa de Juan de la Cruz Cano. ${ }^{34}$ El artículo XII deja sin definir la línea entre los ríos Japura y Negro, solo se refiere a trazar ésta, respetando los asentamientos de ambas coronas.

Cruz Cano, al realizar esta línea posteriormente borrada, intentó situar en el mapa una realidad existente lo más precisa posible. Por ello y una vez informado con los documentos a los que pudo tener acceso, situó las zonas ocupadas por misioneros españoles, las que estaban evangelizadas por portugueses, y una zona despoblada. Pero incluso contando con la buena fe del geógrafo, el asunto no era tan sencillo, pues surgieron muchas incógnitas, entre ellas que no todos los individuos que realizaban la evangelización, sobre todo los de la Compañía de Jesús, eran españoles y

33 Consideraba Alvear estos impuestos moderados, pero se habían reducido desde la expulsión de la Compañía de Jesús (Alvear, 1863, pp. 77-83).

34 Angelis, 1836, “Tratado preliminar de límites 1777....”, Artículos IV, V, VI, VIII, IX, X, XI. 
portugueses, y servían a los reyes de dichas naciones. Tampoco las diplomacias ibéricas tenían por aquellos años del siglo XVIII, la misma fuerza internacional que cuando llegaron a ocupar los territorios por los que litigaban dos siglos después.

Si comparamos esta línea con las señaladas en los anteriores mapas, aquellas de haberse tomado como fronteras, eran mucho más favorables a España, o al menos al sector español que quería mantener más territorios en América.

Situando en el mismo mapa las dos líneas dibujadas por Cruz Cano, aparece entre ellas un espacio, que podría considerarse parecido, al territorio neutral al que se refieren en los artículos del Tratado de 1777, zona neutral y sin ocupación entre España y Portugal, en el Paraguay.

\section{Conclusiones}

Los problemas asociados a la realización, impresión y descontrol en su distribución del Mapa de América Meridional de Juan de la Cruz Cano y Olmedilla de 1775, que se llevaron por delante la reputación de su autor, no estuvieron relacionados directamente con algunas de las líneas que se dibujaron en él, pues estas fueron borradas de casi todos los mapas.

Pero en la obra cartográfica se señalaban muchas más cosas, lugares por donde pasaban los portugueses, zonas ocupadas por estos... y sobre todo mucha información. Es decir, los mejores datos que durante muchos años se pudieron tener sobre América Meridional.

La información geográfica contenida en el mapa disparó los desencuentros que había entre las dos tendencias existentes en la corte de Madrid, que se enfrentaban y seguirían enfrentándose por el poder. Esta misma información, fundamental para realizar las reformas previstas en América por la administración borbónica, no pudo ser controlada por la Secretaría de Estado.

Las reformas fracasaron, y la información terminó en manos de los enemigos de España, que la utilizaron con la finalidad contraria a la que había sido creada.

La cartografía, al decir del profesor Cuesta Domingo, es un arma política, y más en aquellos momentos del siglo XVIII, y como toda arma hay que tener capacidad para manejarla, y tener claro para lo que se quiere usar. Los dos grupos de poder españoles en aquellos momentos querían utilizar el mapa con fines distintos, ninguno consiguió sus objetivos. Tampoco los esfuerzos del ministro Floridablanca, que sustituyó a Grimaldi, consiguieron mantener la información fuera del alcance de los enemigos de España, quienes en 1799 copiaron el mapa conseguido ilegalmente por Thomas Jefferson.

Políticamente el mapa fue un problema y un fracaso para la Secretaría de Estado, fracaso que ellos dirigieron al autor de la obra. Pero desde el punto de vista técnico, geográfico y científico, la obra fue la mejor de su época, como lo reconocieron militares, cartógrafos, y los enemigos de España que la utilizaron. 


\section{Bibliografía}

Alvear de, Diego (1863). La relación geográfica e histórica de la provincia de Misiones, Editor Pedro de Angelis, Imprenta del Estado, Buenos Aires.

Angelis, Pedro de (1836-1837). Colección de obras y documentos relativos a la Historia Antigua y Moderna de las Provincias del Río de la Plata, 6 vols. Buenos Aires, Imprenta del Estado.

Arteaga, Juan José (1999). Las consecuencias del Tratado de Madrid en la desarticulación de la frontera demográfica de a Banda Oriental 1750-1761, Montevideo, Archivo General de la Nación.

Bachiller Cabría, Juan Vicente (2008). Cartografia manuscrita de Brasil en las colecciones españolas (1500-1822), Salamanca, Universidad de Salamanca, Centro de Estudios Brasileños.

Blanco Conde, María (2006). "Mapa histórico de las misiones jesuíticas en el Paraguay". Cuadernos hispanoamericanos, Agencia Española de Cooperación Internacional para el Desarrollo, Madrid. 678:75-83.

Cortesao, Armando y Teixeira da Teixeira da Mota, Avelino (1960-1961). Portugaliae Monumenta Cartographica, 6 vols., Lisboa, Brotéria.

Cortesao, Jaime (1952-1956). Alexandre de Gusmâo e o Tratado de Madrid, 2 tomos, Río de Janeiro.

Cuesta Domingo, Mariano (1974). "Las islas Molucas en la cartografía": Atti del X Congresso Internazionale degli Americanisti. Roma, Vol. I, Génova, Roma.

Cuesta Domingo, Mariano (1996). "La fijación de la Línea de Tordesillas en el Extremo Oriente", El Tratado de Tordesillas: 1482-1518, Setubal, Salamanca, Tordesillas 1994, Madrid.

Cuesta Domingo, Mariano (2002). "Cartografía de América del Sur. Juan de la Cruz", Actas XI Jornadas Nacionales de Historia Militar. Milicia y sociedad ilustrada en España y América (1750-1800). Tomo II. Sevilla, Cátedra "General Castaños" Región Militar Sur, pp. 209-237.

Donoso, Ricardo (1963). "El mapa de la América Meridional de la Cruz Cano y Olmedilla", Revista Chilena de Historia y Geografía, 131:121-175, Santiago de Chile.

Englekirk, John E. (1956). "Franklin y el mundo Hispano", Revista Iberoamericana, XXII(41-42):319-371.

Escudero, José Antonio (2014). El supuesto memorial del conde de Aranda sobre la independencia de América. Ciudad de Méjico, Instituto de Investigaciones Jurídicas. Universidad Nacional Autónoma de México.

Ferrand de Almeida, André (2009). “O Mapa Geográfico de América Meridional de Juan de la Cruz Cano y Olmedilla", Annals of Museu Paulista, 17(2):79-89, Sao Paulo. 
Smith, Thomas R. (1966). "Cruz Cano's map of South America, Madrid, 1775: Its creation, adversities and rehabilitation", Imago Mundi, 20(1):49-78, Taylor \& Francis Online. 